\title{
Awareness and Attitude towards Working in Japan-A Survey on Foreign Students in Japan
}

\author{
Yidan Wang and Rong Zhang
}

\begin{abstract}
The population in Japan has been decreasing rapidly in the recent years. According to the official data, the ratio of people aged over 65 will increase from $26.7 \%$ to $38.4 \%$ in 2060, and the population of Japan will decrease from 1.2711 million to 8808 million by 2065 . Therefore, the shortage in labor force will become a much more serious problem. Japanese government has made efforts to solve this problem through positive policy-making in acceptance of migrants. The number of foreigners reached the maximum level in history in 2016, and the number of foreign students is also increasing. International students are a part of potential labor force. The article discusses the issue of foreign work employment through a questionnaire conducted with 183 international students. The analysis result shows that employment awareness with more tolerance is the key to the solution of some of the hidden problems related to this issue.
\end{abstract}

Index Terms-Employment policy, foreign students, labor shortage, Japan.

\section{INTRODUCTION}

The population of Japan has decreased in birthrate since 2005 (Fig. 1). According to Cabinet Office, Government of Japan the population of Japan now is 1.2711 million, and the ratio of people aged over 65 is $26.7 \%$, in addition, the ratio of $65 \sim 74$ and over 75 is $13.8 \%$ and $12.9 \%$ [1]. It is estimated that by 2065 , the population will go down to 8808 million, and the rate of population aging will rise to $38.4 \%$ from $26.6 \%$ [2]. In aging society of Japan, a significant decrease in the working age population is unavoidable [3], because slower growth of the population will be coupled with a decrease in the labor force arising directly from the falling fertility rate.

In order to overcome the crisis brought about by the decreasing birthrate and the aging population, Japanese government started to promote the employment of women and retirees as supplement to the shortage of labor force [4]. Furthermore, after decades of years of efforts to solve the problem from a domestic perspective, the government finally realized that accepting foreign labor force has become an important step historically to ensure the continuous development of the country. By increasing the supply of foreign labors, Japan reduces the impact of a shrinking workforce and prevents the economy from continuous falling down [5], [6]. In fact, Japan has become more and more internationalized in its labor force market and can be labeled

Manuscript received September 24, 2017; revised December 27, 2017.

Yidan Wang and Rong Zhang are with the Faculty of Design, Nishinippon Institute of Technology, 1-2-11, Muromachi, Kokura-kita, Kitakyushu, Fukuoka, Japan. (e-mail: wyidan@outlook.com, zhang@nishitech.ac.jp). as a new immigration country in this sense.

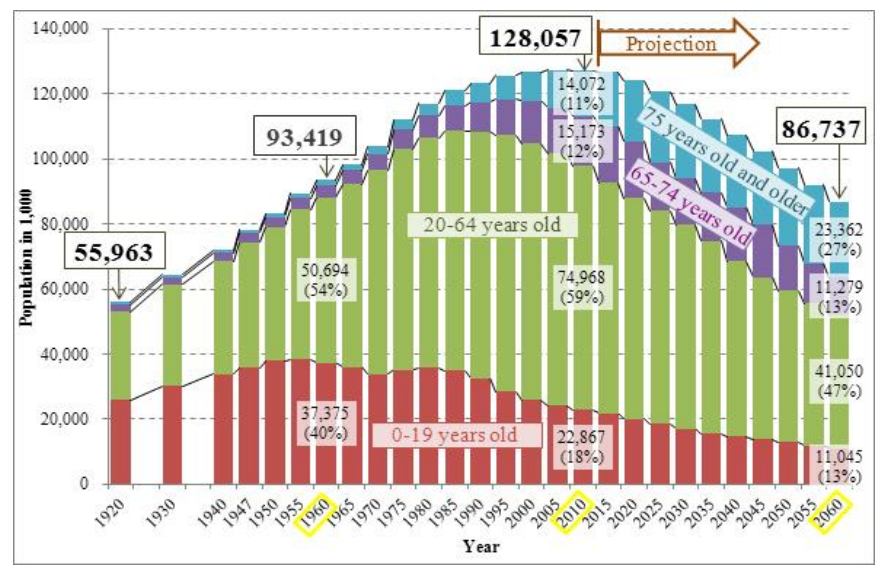

Fig. 1. Population trend by age group in Japan (1920-2060) .

Source: National Institute of Population and Social Security Research, http://www.ipss.go.jp/s-info/e/ssj2014/001.html (retrieved on June 20,2017.)

There has been a rapid increase in the number of foreign students accepted by educational institutions in Japan [6]. According to the data of Japan Student Services Organization [7], the number of registered foreign students was 239,287 persons in May, 2016. This is a $14.8 \%$ increase $(30,908)$ compared with the result of last year. Among them, 68,165 students are learning Japanese at Japanese schools. This figure is a $21 \%$ increase $(11,848)$ compared with the year before. This growth ratio is much higher than the increase $(171,122)$ of students in colleges and universities (12.5\%). Many of the foreign students are doing part-time job during their study in Japan. They actually are contributing much to alleviate the situation of serious force labor shortage [8].

Many of the students consider their study in Japan as their first step towards permanent settlement [9]. They choose to work in Japan and become migrant workers. In 2015, 15,657 students succeeded in job-seeking in Japan. It was more than double the figure 5,878 in 2005 [10]. This is "the result of a government effort to lure skilled professionals, especially in the information technology sector, to boost the global competitiveness of Japanese firms". Japanese government has been active in guiding foreign students for job-seeking in recent years and relaxed restrictions on the working-visa application by foreign students with the purpose that the employment rate of foreign students will be improved from about $30 \%$ at the current stage to $50 \%$ [11].

The purpose of this research is to investigate the awareness and attitude of foreign students towards working in Japan, discover those factors which relate to their job-seeking and employment, and make suggestions on how to remove those 
obstacles affecting their being employed smoothly and enjoying their working in Japan.

\section{LITERATURE REVIEW}

In order to clarify the above issue, literature review is conducted. Unfortunately, very few studies have been found on the issue of how to promote the employment of foreign students after to graduation in Japan. One possible reason for this may be the relatively strong resistance towards accepting immigrants [12]-[14]. A large part of the Japanese citizens are reluctant to accept the fact that they need foreigners to function as a potential supplement to compensate for their labor force shortage.

But in fact, the labor force issue is not a new question Japanese society has to face in the recent years. Japanese government established Training system and Technical Intern Training Program (TITP), whose purpose is "to transfer Skills to Technical Intern Trainees who will form a basis of economic development in their respective countries and play an important role in Japan's international cooperation and contribution"[15]. Many Japanese companies take advantage of unskilled workers they brought from mostly southeast Asian countries and force them to do simple labor work for very low pay. Thus, TITP is widely perceived as the first official attempt of Japanese government to legalize the entry of unskilled and semi-skilled workers into the labor market because the trainees do not receive training but are used as menial labor. [16]. Officially, accepting unskilled workers is not recognized by the law in japan [17]. Therefore, TITP functions as a temporary countermeasure to balance the demand and supply in the pure labor market of Japan, but will not solve the problem on a fundamental basis.

Japan is in need of work labor force at various levels. But the government refuses to open its door to unskilled labors but change the focus into highly-skilled migrants. There is the fear that large-scale immigration could have a significant impact on the society and destroys the stable situation the country has created. Therefore, they continue to allow the participation of unskilled foreign workers in the labor market through back door mechanisms rather than to accept them through a legal device [18]. Policies in regards to low-skilled or unskilled workers are significantly less favorable than highly skilled workers [5]. This is mainly caused by the country's hesitance towards an influx of unskilled foreign nationals.

The concerns about these foreign nationals come from the unpredictability of such migrant influx and the potential measures Japan should think about before it actually happens. On one side, the employment of foreigners has made up for the loss of domestic workers in certain industries, such as work at the construction sites, and assists in the economic development of the country. On the other side, illegal workers have increased, which is an inevitable disadvantage of this issue [19].

Due to the existent problems related to foreign workers, Japanese government is in urgent need to find a way to regulate the precise numbers of foreign labors who enter the country, dynamize the domestic labor market and meet its need for economic growth [8]. This labor-acceptance policy should also be integrated in Japan's effort to seek further possibilities for regional cooperation in South and East Asia because it is closely related to the steadiness in Japan's economic progress from a long run [20]. No matter how much Japanese government has resisted the acceptance of the foreign workers, the trend of globalization and the reality of Japan cannot be ignored [21].

As noted above, Japan promotes the acceptance of only the so-called highly-skilled foreign workers, and low-skill immigration is prohibited by law. This has open side doors in its immigration policy to foreign students [22]. Students who are enrolled in Japanese language schools are the part of unskilled workers [23]. They are indispensable fills for vacancies at late night or early morning shifts at convenience stores which are in business 24 hours a day, at newspaper delivery companies and supermarkets [24]. Japan launched its 100,000 foreign students plan in 1983. Since then, the accepted foreign students have become a relatively stable workforce and contribute in the economic growth of Japan [25]. Actually, foreign worker is the second label for their identity, especially for those who come from developing countries. They performed two roles in their daily lives, students and workers. In 2008, Japan reestablished its plan to accept 300,000 foreign students. This expanded number implies that more foreign students will join the Japanese labor market. Japan made one step further in internationalization, and showed more willingness to accept foreign labors. The group of foreign workers acted by foreign students will expand accordingly. But due to the restriction of the current policy, most of them will disappear from the labor market once they fail to renew their visa after graduation. Japanese government needs to maintain the number of foreign students to prevent a sudden decline in its foreign labor market where they occupied a $21.2 \%$ ratio [26]. More and more foreign students choose to work in Japan and continue their stay after graduation. The number of such students has kept on growth since 2010 [27]. But the problem is that about $50 \%$ of the foreign students are unable to obtain permission for the transformation of their student visa into a working visa [28]. Companies who employ foreign graduates are supposed to prove that they are doing highly-skilled work. This suggests a high gap between the actual need of the labor market towards foreign students and the attitude of the Japanese government. The role of foreign students should be redefined and more reliable regulations are in need to benefit both the Japanese companies and foreign students.

This article investigates the awareness and attitude of foreign students towards their working and job-seeking in Japan, clarifies some of the practical problems the administrators have to face and makes suggestions on countermeasures to promote the employment process of foreign students.

\section{Methodology}

The focus of this study is to discover the intention of the 
foreign students in their future career through a survey and a semi-controlled interview. 183 international students who are studying in educational institutions in Kitakyushu participate in the survey. 10 questions regarding their expectation and experience at work were assigned to each participant. Then, a semi-structured interview with 15 foreign students was conducted.

The 183 participants include 94 females and 89 males. 7 of them are still under the age of 18, with 106 participants aged 19 23, 62 aged 24 28, and 8 are over 29.

They come from three countries, China, Nepal and Vietnam. The number of Chinese students is the largest. The numbers of students from Nepal and Vietnam have grown significantly for the past five years [2]. This means that more young people from these two countries are entering Japanese labor market.

Among the 183 participants, 166 students, including 73 Chinese, 54 Vietnamese and 39 Nepalese, have had working experience Japan. Some of the students rely on their families for financial support and have not worked. This study uses the data of these 166 students as valid samples. Among these 166 students, 78 students are studying in Japanese language schools, 29 from vocational schools, 5 from two-year junior colleges, 48 from four-year universities, and 6 from graduate schools.

15 participants had a semi-controlled interview with the one of the authors. She has been working as a part-time worker for about a year and half at convenient stores and has kept a relatively close relationship with the interviewed students. The 15 participants who accepted the interview are from three countries -- China, Nepal and Vietnam. The six Chinese students are all studying in universities. One of them is now working part-time at a Japanese construction company. The five Vietnamese consist of three students from vocational schools and two students from Japanese language schools. Among the four Nepalese students, three are studying at two-year colleges and one is working in a trading company. For some of the interviewees, the author even knows well about their family members. It is firmly believed that the information included in this study is reliable because they were obtained through private conversations and daily interactions. The opinions of the respondents are honest and truthful.

\section{TABLE I: SURVEY QUESTIONS}

\begin{tabular}{|c|}
\hline $\begin{array}{l}\text { Q1. Why did you come to Japan? } \\
\text { a. To learn Japanese language and obtain a degree. }(50.3 \%) \\
\text { b. To find a job in the future. }(31.7 \%) \\
\text { c. To settle in Japan }(1.6 \%) \\
\text { d. To earn more money. }(6 \%) \\
\text { e. Others. }(10.4 \%)\end{array}$ \\
\hline $\begin{array}{l}\text { Q2. What kind of work have you been doing in Japan? } \\
\text { a. At restaurants }(47 \%) \\
\text { b. At convenience stores }(48.6 \%) \\
\text { c. Distributing pamphlets }(4.9 \%) \\
\text { d. Cleaning }(10.4 \%) \\
\text { e. Private tutoring }(8.7 \%) \\
\text { f. Translation }(6 \%) \\
\text { g. The others }(12 \%) \\
\end{array}$ \\
\hline $\begin{array}{l}\text { Q3. What is the proportion of foreigners at your current workplace? } \\
\begin{array}{ll}\text { a. Under } 30 \% .(42 \%) & \text { b. } 30 \% \sim 50 \% .(36.1 \%) \\
\text { c. } 50 \% \sim 70 \% .(15.3 \%) & \text { d. Over } 70 \% .(6.6 \%)\end{array}\end{array}$ \\
\hline
\end{tabular}

Q4. Why do you do part-time job?

a. For living and expense $(43.2 \%)$

b. For career experience $(21.9 \%)$

c. For money. (10.4\%)

d. To learn Japanese language and culture $(19.1 \%)$

e. Others $(5.4 \%)$

Q5. Do you enjoy doing the work at your current workplace?

a. Yes, absolutely. (47.5\%) b. I feel ok. (16.9\%)

c. Have no idea. $(10.9 \%)$

d. Not satisfied $(13.1 \%)$

e. No, absolutely not. (11.6\%)

Q6. What makes you feel embarrassed at your workplace?

a. I can't communicate sufficiently with Japanese colleagues. (57.9\%)

b. I don't know how to get access to information related to job seeking. $(18 \%)$

c. I was rejected when I tried to find a job because of my foreigner identity. $(32.8 \%)$

d. I am not paid the same as Japanese. (11.5\%)

e. I don't know how to work due to insufficient training $(10.9 \%)$

f. Others. (4.4\%)

Q7. How do you think of the guidance you received during the internship period?

a. There is a tentative training for work procedures and business manners. $(50.8 \%)$

b. There is no special training for business manners. $(20.8 \%)$

c. There is no special training for work procedures. $(20.2 \%)$

d. There is no training at all. $(8.2 \%)$

Q8. What are your concerns in handling issues related to interpersonal relationship with your colleagues?

a. I try to talk with my Japanese superior. (32.2\%)

b. I just ignore. (37.1\%)

c. I know I am being bullied but can receive support from nobody. (15.3\%)

d. I discuss with my colleagues. $(31.1 \%)$

e. I will resign. (7.7\%)

Q9. What do you think of the stresses when you work in Japan?

a. I can't bear. (19.1\%)

b. I can endure though it is very difficult. $(37.7 \%)$

c. I have no idea. $(14.8 \%)$

d. I don't have much stress. $(28.4 \%)$

Q10. What makes you dissatisfied with working in Japan?

a. I am not employing my professional skills at workplace. (37.2\%)

b. There is too much trouble in the relationship with other Japanese colleagues. $(54.1 \%)$.

c. It is pure physical work and I am feeling exhausted. (17.5\%)

d. It is difficult to have the support from my Japanese superior. (10.4\%)

e. I don't have sufficient time for job-seeking after graduation due to the limited visa duration time. (15.3\%)

$\mathrm{f}$. It is difficult to become a full-time employer because of my deficiency in Japanese languages and culture understanding. (16.4\%)

g. I hate to be treated the same as Japanese (12.6\%).

h. Others. $(15.9 \%)$

10 questions with multiple choices are included in the survey (Table I). Students can make free comments on the questions. The questions for the semi-controlled interview function as a supplement to these questions. The answers from the participants are also indicated in Table I by ratios to each option of the questions.

\section{RESULTS AND DISCUSSION}

\section{A. Awareness and Attitudes towards Job-Seeking in Japan}

The result of Q1 (Why did you come to Japan?) shows that $50.3 \%$ of students come Japan to learn Japanese language and obtain a degree in higher education. This suggests that about half of the students don't have the desire or motivation to work in Japan for their whole lives. They certainly should not be treated as the compensation for the scarcity in Japanese labor force market. $31.7 \%$ of international students (58 students) 
think come to Japan with the purpose to find a job after graduating from schools. The students can be divided into two categories. One group refers to students who have professional experience at work before coming to Japan, but can't speak Japanese. They are doing part-time work for the purposes of both Japanese acquisition and accumulation of working experience. Another group of students just want to work in Japan for money at the current stage. They have no professional experience and can't speak Japanese well. In order to get relatively higher pay, they do pure labor work which is not preferred by the local people and have to endure the terrible working environment and conditions. It is difficult for them to get a working visa after graduation because they are not considered highly skilled. They usually choose to lie to the administration during visa application. Their employers will help to provide fake documents because these students are usually the most hard-working among all employees. Their goal is very clear - to take advantage of every minute they stay in Japan and increase their income as much as possible. This serves as the main reason for the influx of the foreign students into the labor force market of Japan [29]. 6\% of the students come to earn money for a short period of time. They registered as full-time students because it is only possible way for them to obtain a visa. They made use of the students identity to meet their working needs.

Optimistic results are available from answers of Q2 to Q5. The results of Q2 (What kind of work have you been doing?) indicate that $48.6 \%$ of the students (89 students) have the experience of working at convenience stores and $47 \%$ of the students (86 students) have worked at restaurants. This suggests that foreign students are commonly accepted by Japanese companies to do service related jobs. They are an important part of the labor force for the service industry in Japan.

According to the answers to Q3 (What is the proportion of foreigners at your current workplace?), $21.9 \%$ of the students (40 students) indicate that more than $50 \%$ of their colleagues are foreigners. This high proportion once again proves that foreign students are contributing significantly to the development of service industries. About the reasons for doing part time jobs $(\mathrm{Q} 4$. What is the reason for your doing part-time job?), $21.9 \%$ of the foreign students (40 students) state that they want to learn professional skills which they can use for their future career, and $19.1 \%$ of the students say that they want to learn Japanese language and know more about the culture through work. Furthermore, about half of the international students chose the option that they want to continue to work at the workplace where they are doing the part-time job right now (Q5. Do you enjoy doing the work at your current workplace?).

From the semi-controlled interview, it is found that most students, who will graduate from vocational schools and universities, are confused about what to do in order to succeed in their job-seeking after graduation. There is not much demand for foreign students to do skillful work if they are paid the same as Japanese. Because they are labeled as foreigners, Japanese companies tend to show prejudice against their identity. Foreign students are not treated the same as Japanese applicants. This is out of the expectation of Japanese government that foreign students should engage more in highly-skilled work after graduation. In order to continue their stay in Japan, many students are told by their part-time employers that they could be hired as lowly-skilled workers. But the companies would help them to achieve the visa as highly-skilled workers. Clearly, Japanese government will fail in its original plan and have to suffer from this cheating game

\section{B. Accommodation to the Japanese Culture}

In answers to Q6 (What makes you feel embarrassed at your workplace?), 57.9\% of the respondents (106 students) agree that deficiency in Japanese language has become the biggest factor affecting their job-seeking. Many companies refuse to hire them because of the concern that foreign students may not function well in Japanese [31]. This is especially a more serious problem with students from Nepal and Vietnam. Japanese characters are more challenging for them because of the distinct difference between their native languages and Japanese. The complicated strokes of Chinese characters and the diverse forms of expressions in Japanese language are the obstacle for their Japanese learning. It takes them much longer time to master Japanese language and pass the proficiency test. Although many of the Nepalese and Vietnamese students can speak good Japanese, they are not unable to read and write well. This is also the reason why many Nepalese choose to go to vocational schools. Their Japanese proficiency prevents them from completing higher education smoothly. Japanese is only official language in Japan and very few Japanese people can communicate in English. Therefore, official documents are in Japanese only in most cases. Japanese companies would not hire foreigners who cannot meet their requirement for document understand and creation.

$32.8 \%$ of the students replied that they were rejected when looking for a job due to their foreigner identity. Although some of them have excellent Japanese ability and desirable working experience, the employers tend to show bias towards their foreign background. They are not familiar with regulations for foreigner administration and are not sure what to do in order to access the necessary information. They assume that the recruitment of foreign employees may bring them potential trouble in management. This actually serves as the main factor hindering the full entry of foreigners into the Japanese companies.

In Q7 (How do you think of the guidance you received during the internship period?), $20.8 \%$ of the foreign students (38 students) indicate that they received simple training as trainees for several weeks, but did not learn about the courtesy for business scene. In Japan, courtesy learning is an important part of the integration of students into the society after graduation, including Japanese students. But this is much more challenging for foreign students because of the different culture where they were brought up. Foreign students rely on the simple introduction from their managers before they start the part-time job. It is obviously not enough, especially in the case that they are providing service to Japanese customers. 
Japanese culture requires that service providers should make their customers $100 \%$ satisfied and comfortable. This is a basic rule for all business cases. Japanese customers make judgment about the service quality using the same criterion. This makes the Japanese companies hesitate in hiring foreigners, because courtesy problem may bring about so much trouble for them and destroy their reputation. Foreigners are assimilated rather than respected during the process of accommodating to Japanese culture [12]-[14].

In Q8 (What are your concerns in handling issues related to interpersonal relationship with your colleagues?), $32.2 \%$ of the students report that they will ask for help from their superior when they have trouble their interpersonal interactions with their Japanese colleagues at workplace, while $31.1 \%$ prefer to handle the problem by discussing with other colleagues. From the afterwards interview, we find that most of these problems by the deficiency of the foreign students. There are many euphemistic expressions in the daily dialogue of Japanese which may cause misunderstanding. But it is very difficult for foreigners to fully understand if they are not advanced learners. Japanese tend to avoid face-to-face discussion when they spot a problem at work. They may either hide their complaints or report to the manager directly. Foreigners need to learn how to solve the problem through the intervention of the manager. It is a most important part of the process of positive integration into Japanese culture. Since foreigners are excluded from the community of Japanese, foreign students have their own community to discuss problems they have to face at workplaces. In all, the current Japanese society is not tolerant enough with foreign students, even though they show a positive attitude in working. More mutual understanding is needed if Japan wants to create a social environment for foreigners with a variety of cultural backgrounds. $37.1 \%$ of the students recognize they are unable to improve the interpersonal relationships at their workplaces with their own effort. The solution of interpersonal problems lies in both parties.

According to Q9 (What do you think of the stresses when you work in japan?), 19.1\% of the respondents (35 students) reply that the pressure is more than they can bear. Japanese society is famous for its high suicide commitment rate around the world. The stressful situation creates many psychological problems for the residence. Even Japanese people have to endure bullying at workplaces sometimes. Many foreigners are afraid of being bullied and decide to give up trying. 37.7\% respondents (69 students) say that the pressure in their daily life is huge but still tolerable. Japan's working environment has been criticized for creating extra pressure for working staff, and thus, Japan has been a country with a high ratio of suicide. For foreigners, they have to burden much more than the local Japanese. Before they can adapt themselves to Japan's unique hierarchical relationship, they are supposed to be unconditionally obedient at work as a subordinate. That is, as a subordinate, he/she has to obey orders from their senior colleagues. Sometimes, the senior colleagues are staffs who have entered the workplace only several days earlier. But this is one of the fundamental features of Japan in maintaining its social order and all members of this society are forced to follow in order to survive.

Interestingly, about $43.2 \%$ of the respondents show relatively optimistic attitude towards the pressure in Japanese society. $14.8 \%$ of the students just take it for granted and don't care much. $28.4 \%$ of students claim that they have never felt any pressure at all. The reason for this is that these students are still enjoying the fresh feeling when facing a new culture. They do not regard themselves as part of the stressful culture. They prefer to separate themselves from the surrounding and tend to treat the pressure they have at workplaces as a new cultural experience and part of their learning process. There is also the possibility that they would not want to get involved in very sensitive problems at workplaces because of their foreigner identity.

\section{Support is Needed from Administration}

Q10 (What make you dissatisfied with your working in Japan?) shows the huge gap between the expectation of foreign students and the current situation. $37.2 \%$ of the respondents emphasize that their professional skills are not paid enough attention to at their current work. Foreign students are more anxious to learn about professional work and get prepared for their future job-seeking. However, at the current stage, most of them are assigned to do work which does not require specific skills. Generally, they are excluded from candidate list at workplaces to receive off-job and on-the-job training for a higher level. Therefore, doing work at service industry has become their only device for making a living in Japan. The large number of lowly-skilled foreign workers is not officially recognized by the government, but they are an indispensable section of the Japanese labor force market.

As mentioned above, foreign students are working in Japan for relatively higher pay they can receive than their home countries, along with the stable social environment and the sound welfare system. These benefits are a great attraction and the strong force to push them for job seeking. But they have no chances to receive training about the complicated process for job seeking in Japan. The part time job offers them the opportunity to learn about the society, although far from sufficient. They are anxious to know more about the employment situation in Japan, but are not provided much guidance. Workplaces, such as the convenience stores and restaurants have lower thresholds than other industries and are easy to enter. The vague information they receive from their part-time workplace helps them build up an unclear concept regarding their job-seeking after graduation.

When apply for a working visa, foreign students are required to show evidence that they are qualified for highly skillful jobs and their role cannot be replaced by Japanese. Even though the companies have a strong willingness to hire the foreign students, they may be rejected in the application if they are not considered qualified as a highly-skillful worker. This fact does not correspond to the actual demand of Japanese labor market. In the case of a society with serious labor shortage, administers in Japan should enact policies 
based on the current situation. The solution to this problem will not only balance the demand and supply at the domestic labor market, but also remove the difficult interactions between the employers and foreign students. Thus, promote the internationalization process of the country and create a good reputation for its future.

The current policy in Japan for work visa application has restricted the possible employment of foreign students after their graduation. Even when fraud information is submitted to the immigration bureau and the inspectors make judgment based on the documents provided. Companies which hire lowly-skilled foreigners get involved in the cheating process, and are cooperating with the foreign students. There are companies which even promise to continue the employment of the foreign students, even if they won't have a valid visa for future stay in Japan. The current situation makes the Japanese administers being isolated from the other two parties.

\section{CONCLUSION}

In terms of receiving foreigner labor forces, Japan, as a developed country, has lagged far behind [30]. Although foreign labors have contributed to the economy and compensated for the intensified decrease in labor shortage, Japanese government has maintained a wait-and-see attitude for decades of years in its policy-making. Instead of enacting more favorable policies to promote employment of foreign students, Japanese government issued more student visas and allowed overseas students to work longer hours (from 20 hours to 28 hours per week). Japan needs foreign labors and its dependence degree on foreign labors has deepened in recent years [31]. Foreign students are not provided with sufficient chances to settle in the country and make use of the skills and knowledge they learn during college to work after graduation. There is no effective support to foreign students for their recruitment process. Japanese government needs to build a bridge enterprises and students so that their communication can be strengthened. Administrative support should also include distribution of such information to more communities and orientation seminars on visa application requirements and managerial procedures for foreign settlers.

Japan, as a non-immigrant country, has been unwilling to open its door and accept new immigrants. The current labor policy of Japan rejects the low-end labor force to work legally. From a long run, this is going to hinder the development of country in many industries. The urgent need in the labor market for lowly-skilled workers suggests that Japan should accept more foreign students as potential work force. Many foreign students learning in Japan have a positive attitude towards job-seeking and the companies show strong willingness to accept them. But due to the deficiency in Japanese language and the unique cultural features have become a barrier for smooth recruitment. This undesirable situation has been enhanced by the harsh restrictions on working visa application. Japanese administers should enact employment-promotion policy based on the current situation, and help remove those obstacles for foreigner recruitment.
Effective policies in the promotion will sustain a relatively stable work labor source from a long run, which is the substantial support for the economic growth in Japan. Foreigners are one important power supporting the Japanese economy. It is an undeniable fact and Japanese government should realize this and offer more guidance to its residents and companies in order to create more relaxing atmosphere for foreigners. Japanese society should learn to accept the diverse aspects in foreign cultures and make Japan a more tolerant society with ethnic differences.

The current policy of Japanese government shows the gap between the official requirements for working visa application and the reality at the domestic labor force market. The ignorance of the large number of foreign students working at the service industry will drive the potential work force from the country. The recruitment pressure will not be alleviated and Japanese companies will have to struggle with the serious labor force shortage problem.

Japanese government should change its focus by paying more attention to the real needs of the Japanese companies and offer substantial support to ease the strong demand for lowly-skilled labors. Foreigners who are willing to do the unfavorable work in Japan contribute to the prosperity of country the same as highly-skilled workers. More chances should be provided to them for job-seeking and pre-job training in order to help them better accommodate to the social requirements.

\section{REFERENCES}

[1] Cabinet Office, Government of Japan. (April 20, 2017). Countermeasure of declining birthrate 2017. [Online]. Available: http://www8.cao.go.jp/shoushi/shoushika/index.html

[2] National Institute of Population and Social Security Research. (June 22, 2017). [Online]. Available: http://www.ipss.go.jp/syoushika/tohkei/Popular/Popular2017.asp?chap $=0$

[3] N. Ogawa and R. Matsukura. (May 10, 2017). Ageing in Japan: The health and wealth of older persons. in Proc. the United Nations Expert Group Meeting on Social and Economic Implications of Changing Population Age Structures Japan, 2005. [Online]. Available: http://www.un.org/esa/population/meetings/Proceedings _EGM_Mex_2005/ogawa.pdf

[4] Prime Minister of Japan and His Cabinet. (June 2016). Japan revival strategy 2016. [Online]. Available: http://www.kantei.go.jp/jp/singi/keizaisaisei/pdf/2016_zentaihombun.pd f

[5] D. Tolliver. (April 27, 2016). Japan \& immigration - Pacing labor Growth during Japan's demographic decline. [Online]. Available: http://danielletolliver.com/assets/danielle-tolliver_ asns-capstone-paper.pdf

[6] M. Yamada, "The current issues on foreign workers in Japan," Japan Labour Review, vol. 7, no. 3, pp. 5-18, 2010.

[7] Japan Student Services Organization. (June 20, 2017). International Students in Japan 2016. [Online]. Available: http://www.jasso.go.jp/en/about/statistics/intl_student/data2016.html

[8] M. Ogawa, "Current issues concerning foreign workers in Japan," Japan Labor Review, vol. 2, no. 4, pp. 6-24, 2005.

[9] C. F. Shao, "Japanese policies and international students in Japan," in Proc. the 17th Biennial Conference of the Asian Studies Association of Australia, Melbourne, 1-3 July, June 10, 2017.

[10] The Japan Times. (November 2016). Record number of foreign students find work after graduating Japanese universities in 2015. [Online]. Available:

http://www.japantimes.co.jp/news/2016/11/16/national/recordnumber-foreign-students-find-work-graduating-japanese-universities-20 $15 /$

[11] Japan Student Services Organization. (2016). About promoting the employment of international student. [Online]. Available: 
http://www.jasso.go.jp/gakusei/career/event/guidance/_icsFiles/afieldf ile/2016/06/29/12_h28guidance_ryugakuseission_monkasyou.pdf

[12] R. Zhang and D. McCornac, "Intercultural awareness via improvements in intercultural communication: The need for change in Japan," Journal of Intercultural Communication, Issue 32, 2013. Goteborg, Sweden: Immigrant Institute.

[13] R. Zhang and D. Steele, "Improving intercultural awareness: A challenging task for Japan," Procedia-Social and Behavioral Science. vol. 47, pp. 52-63, 2012. Amsterdam, Holland: Elsevier.

[14] R. Zhang, "International or self-conscious? -- A slip of Japanese government in policymaking," Studies in Contrastive Linguistics (edited by Figueroa, C. M. \& Garate, T. I. M.), pp. 1091-1098. Universidade de Santiago de Compostela, Spain

[15] Japan International Training Cooperation Organization (JITCO). Technical intern training guidebook for technical intern trainees (2010). [Online]. https://www.jitco.or.jp/download/data/guidebook_english.pdf

[16] N. Oishi, "Training or employment? Japanese immigration policy in dilemma," Asian and Pacific Migration Journal, vol. 4, no. 2-3, 1995.

[17] K. Sugeno, Labor Situation in Japan and Its Analysis: General Overview 2015/2016, Tokyo, Japan: The Japan Institute for Labour Policy and Training.

[18] S. van Rijn. Leaving the back door ajar -- Unskilled foreign workers in Japan. Leiden University. [Online]. Available: https://openaccess.leidenuniv.nl/bitstream/handle/1887/ 40939/SUZANNE\%20VAN\%20RIJN_1375423_PEIR_THESIS_SEMI NAR_LEAVING THE BACK DOOR_AJAR_UNSKILLED_FOREI GN_WORKERS_IN_JAPAN.pdf?sequence $=1$

[19] H. Shimada, "The employment of foreign labor in Japan," The Annals of the American Academy of Political and Social Science, vol. 513, no. 1, pp 117-129, 1991

[20] Y. Igushi, "Asia strategy on international migration," Policy Research Institute, Ministry of Finance, Japan, Public Policy Review, vol.10, no.1, pp. 109-151, March 2014

[21] J. P. D. Pollock. (2016). Breaking down the walls of Japan-- Japan's slow international integration. Skemman. [Online]. Available: http://skemman.is/item/view/1946/26067

[22] D. Chiavacci, "Japan in the 'global war for talent': Changing concepts of valuable foreign workers and their consequences," Asien: The German Journal of Contemporary Asia, vol. 124, pp. 27-47, 2012.

[23] K. Yamanaka, "New immigration policy and unskilled foreign workers in Japan," Pacific Affairs, vol. 66, no. 1, pp. 72-90, 1993.

[24] H. Mori, "Migrant workers and labor market segmentation in Japan," Asian and Pacific Migration Journal, vol. 3, no. 4, pp. 619-638, 1994.
[25] C. Ishikawa, "Education-oriented Immigration in Japan and the legacy of the 'Plan to accept 100,000 foreign students," Journal of the Education Center for International Students, vol. 4, pp. 5-26, Oct. 2006.

[26] Ministry of Health, Labor and Welfare. (Journal 2016). The employment situation of foreigner (by 2015.10). [Online]. Available: http://www.mhlw.go.jp/stf/houdou/0000110224.html

[27] Ministry of Justice. The employment situation of foreign students in Japanese companies (2015). [Online]. Available: http://www.moj.go.jp/content/001207275.pdf

[28] Ministry of Education. Culture, sports science and technology-Japan. Promoting the Job-seeking of Foreign Students. [Online]. Available: http://www.jasso.go.jp/gakusei/career/event/guidance/_icsFiles/afieldf ile/2016/06/29/12_h28guidance_ryugakuseission_monkasyou.pdf

[29] World Watching. The actual situation of 1million foreign workers era--working foreign Students. [Online]. Available: http://www.nhk.or.jp/kokusaihoudou/archive/2017/02/0217.html

[30] R. Zhang and D. McCornac, "Intercultural awareness via improvements in intercultural communication: The need for change in Japan," Journal of Intercultural Communication, Issue 32, 2013, Goteborg, Sweden: Immigrant Institute.

[31] N. Oishi, "The limits of immigration policies: The challenges of highly skilled migration in Japan," American Behavioral Scientist, vol. 56, no. 8 pp. 1080-1100, 2012.

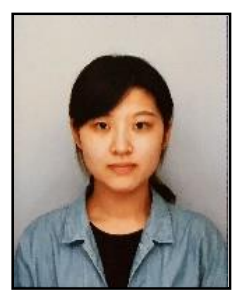

Yidan Wang was born in Liaoning Province, China. She came to Nishinippon Institute of Technology, Japan as an exchange student in 2015. She received her bachelor degree from Liaoning Institute of Technology, China She is currently a research student in the above university in Japan. Her research focuses on issues related to internationalization and foreign students in Japan.

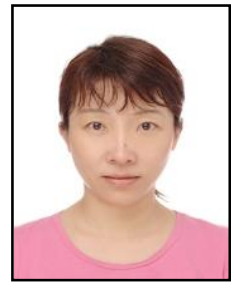

Rong Zhang received her bachelor degree from Dongbei University of Finance and Economics, China in 1993. She received her M. Ed. degree from Fukuoka University of Education, Japan in 1998 and her Ph.D at the Graduate School of Information, Production and Systems, Waseda Unviersity, Japan in 2014. She has been teaching both English and Chinese in Japan for more than twenty years. Since April 2005, she has been an associate professor at Nishinippon Institute of technology, Japan. Her research focus includes foreign language teaching, e-learning and intercultural communication study. 